\title{
Simple Procedures for the Rapid Cleavage of Ester Lipids and for the Large-Scale Isolation from Brain of Cerebroside Sulfate
}

\author{
Atsushi HARA ${ }^{1}$ AND Norman S. RADIN ${ }^{2}$
}

\begin{abstract}
Mental Health Research Institute (Department of Psychiatry) and Department of Biological Chemistry, University of Michigan, Medical School, Ann Arbor, Michigan 48109
\end{abstract}

Received June 26, 1979

\begin{abstract}
The ester groups of glycerophospholipids in tissue extracts can be cleaved in less than 10 min at room temperature if the lipids are extracted with hexane-isopropanol and the filtrate is treated with methanolic $\mathrm{NaOH}$. The resulting mixture can be treated with aqueous $\mathrm{Na}$ sulfate containing sulfuric acid and partitioned to remove the inorganic reagents and hydrophilic ester degradation products. When the procedure is applied to brain lipid extracts, the addition of alkali produces a second, lower phase that contains much of the hydroxycerebroside, virtually all of the sulfatide in the extract, and small amounts of other lipids. The sulfatide can be isolated from the lower phase by neutralizing it with $\mathrm{HCl}$ in aqueous methanol, and partitioning with chloroform to remove nonlipid components. The lower phase is evaporated to dryness and treated with periodic acid to convert the cerebroside to a less polar product. The lipids recovered from the reaction mixture are then fractionated with a Florisil column, which yields highly purified sulfatide. Starting with $300 \mathrm{~g}$ of pig brain one can obtain about $1.1 \mathrm{~g}$ of sulfatide in 4 working days, using conventional, compact equipment. Since the precipitation step is almost complete, and the procedure can be scaled down to very low levels, the method has promise for quantitation methods and isotopic studies of sulfatide metabolism.
\end{abstract}

Various procedures (1-9) have been offered for the isolation from brain tissue of cerebroside and sulfatide (cerebroside sulfate) but all the methods utilize toxic, unstable expensive solvents, particularly chloroform, which has recently been implicated as a carcinogen (10). Moreover, the available methods for sulfatide isolation on a preparative scale consume large amounts of solvent and adsorbent. Most of the procedures produce sulfatide salts of unknown cationic composition. We have been investigating the potential of solvent systems based on hexane and isopropanol after seeing the

1 Present address: Department of Biochemistry, Institute of Adaptation Medicine, Shinshu University, Matsumoto, Japan.

${ }^{2}$ To whom requests for reprints should be sent. promising separations produced by Geurts van Kessel et al. (11).

We have described the use of $\mathrm{H}-\mathrm{IP}^{3}$ for extracting lipids from tissues (12) and for the large-scale isolation of lecithin (13). Further study showed that H-IP extracts could be treated with methanolic $\mathrm{NaOH}$ at room temperature to cleave the lipid esters, even in the presence of the water from the original tissue sample. When we tried a concentrated solution of $\mathrm{NaOH}$ with a brain extract, we made the unexpected discovery that the alkali formed a small amount of a second liquid phase that contained not only much of the alkali, but also a precipitate

\footnotetext{
${ }^{3}$ Abbreviations used: $\mathrm{H}$, hexane; IP, isopropanol; C, chloroform; $M$, methanol; $W$, water; tlc, thin-layer chromatography.
} 
consisting of much of the hydroxy acid cerebroside, virtually all the sulfatide, and small amounts of the other alkali-stable lipids. This fortuitous observation suggested that the step would be useful for the preparative isolation of the $\mathrm{Na}$ salt of sulfatide. It was possible to isolate sulfatide from the lower phase by conventional silica gel column chromatography but a small proportion of the hydroxycerebroside and traces of other lipids contaminated the product. The problem was solved by oxidizing the cerebroside with periodic acid, which produced a less polar product that could be more completely separated from the sulfatide.

We hope that the increased availability of cerebroside sulfate will promote its use in liposomes, as a replacement for dicetyl phosphate, and in physiological studies, as in its suggested roles as a morphine binder (14) or in salt transport (15). The easy availability of sulfatide should encourage studies of its chemistry and the preparation of radioactive sulfatide by chemical methods (16).

\section{MATERIALS}

Hexane ("nonspectro") and cyclohexane were commercially redistilled solvents from Burdick \& Jackson Laboratories. Isopropanol, ACS grade, was redistilled in our glass still. Sulfatide, labeled with $\left[{ }^{14} \mathrm{C}\right]-$ lignoceric acid by a new method, was kindly furnished by Dr. Yasuo Kishimoto. Labeled galactocerebroside was prepared as described before (17). Frozen pig brain was bought from a meat market. Eriochrome Black $T$ came from Eastman Organic. Florisil 60/100 mesh (a coprecipitated magnesia-silica gel) was obtained from Fisher Scientific Corporation.

Samples were examined by tlc on silica gel plates, using $\mathrm{C}-\mathrm{M}-\mathrm{W}$ 65:25:4 (mixture ratios are $\mathrm{v} / \mathrm{v} / \mathrm{v}$ ) or $\mathrm{C}-\mathrm{M}-\mathrm{W}$-ammonium hydroxide 70:30:4:1 for development, and a charring or ninhydrin spray for locating the spots. Elemental analyses were carried out by Spang Microanalytical Laboratory and Galbraith Laboratories.

\section{PROCEDURE}

A lipid extract was prepared from $300 \mathrm{~g}$ of pig brain as described before (12). The homogenate in $5400 \mathrm{ml}$ of H-IP 3:2 was filtered with a 3000-ml sintered glass (coarse porosity) Buchner funnel under gravity into a 2-gallon bottle. The proteinaceous residue was washed with $2 \times 900 \mathrm{ml}$ of the same solvent. The filtrate volume was adjusted to $7500 \mathrm{ml}$ with the solvent. To the filtrate was added $150 \mathrm{ml}$ of $5 \mathrm{M} \mathrm{NaOH}$ in methanol, in small portions with rapid mixing, and mixing was continued for $15 \mathrm{~min}$. The precipitate was allowed to settle about $1.5 \mathrm{~h}$ and the upper layer was removed with a suction tube.

The mixture of lipids and alkali was neutralized by addition of $0.1 \mathrm{ml}$ of bromcresol purple solution $(2.5 \mathrm{mg} / \mathrm{ml})$ and enough ice-cold methanol-concd $\mathrm{HCl}$ 1:1 to produce a yellow color. This took about $106 \mathrm{ml}$. The mixture was stirred rapidly during the neutralization to minimize overtitration, which could be corrected with a little $\mathrm{NaOH}$. Chloroform was added before neutralization was complete, in a volume equal to the amount of methanol- $\mathrm{HCl}$. The chloroform helped the precipitated lipids dissolve and release trapped $\mathrm{NaOH}$. The liquid was transferred with the aid of $650 \mathrm{ml}$ of $\mathrm{C}-\mathrm{M}$ $2: 1$ and $150 \mathrm{ml}$ water to a $2000-\mathrm{ml}$ separatory funnel whose walls had been marked at 100- or 200-ml intervals with a carborundum grinding tool. The volume of water was chosen to yield a partition system in which the upper-layer volume was about $40 \%$ of the total, as in the partition system of Folch et al. (18).

At this stage the upper layer contained the hydrophilic degradation products from the ester-type lipids, $\mathrm{NaCl}$, isopropanol, methanol, and water. The lower layer, which contained about $5 \mathrm{~g}$ of lipid, part of the $\mathrm{pH}$ indicator, and a small amount of 
$\mathrm{NaCl}$, was evaporated to near dryness with a rotary vacuum evaporator. The residue was stirred in the same flask for $2 \mathrm{~h}$ in the dark with $240 \mathrm{ml}$ of methanol, $50 \mathrm{ml}$ of chloroform, and $90 \mathrm{ml}$ of $0.2 \mathrm{M}$ paraperiodic acid (19). The mixture was cloudy at first but eventually became clear. The solution was treated with additional bromcresol purple and $10 \mathrm{~N}$ aqueous $\mathrm{NaOH}$ to yield a blue color. A "Folch partition" was again prepared by adding $430 \mathrm{ml}$ of chloroform and $90 \mathrm{ml}$ of half-saturated $\mathrm{NaCl}$ solution. The upper layer, containing excess periodate, iodate, indicator, and formate, was removed and the lipoidal layer washed with $360 \mathrm{ml}$ of $\mathrm{M}-\mathrm{W} 1: 1$. The lower layer was then evaporated to dryness, the residue extracted with portions of C-M 2:1 $(80 \mathrm{ml}$ total) to remove inorganic salts, and the solvent displaced with cyclohexane by stepwise vacuum evaporation. The cyclohexane-lipid solution was lyophilized, yielding about $4.3 \mathrm{~g}$ of powder.

Column chromatographic purification was accomplished with $200 \mathrm{~g}$ of Florisil packed in chloroform in a column $3.1 \mathrm{~cm}$ in diameter (the packing was $45 \mathrm{~cm}$ high). The packing was rinsed with $80 \mathrm{ml}$ of $\mathrm{C}-\mathrm{M}$ 95:5, the sample was added as a solution in $43 \mathrm{ml}$ of the same solvent, and the column was eluted with $2000 \mathrm{ml}$ of C-M 90:10,2000 $\mathrm{ml}$ of C-M 85:15, and $4000 \mathrm{ml}$ of C-M $70: 30$. Only slight pressure was needed to obtain a flow rate of about $15 \mathrm{ml} / \mathrm{min}$. Fractions of $400 \mathrm{ml}$ each were collected (20) and $0.05-\mathrm{ml}$ aliquots were analyzed by tic.

The nonpolar lipids, mainly oxidized cerebroside, eluted in the first $500 \mathrm{ml}$ and sulfatide began to elute after about $3000 \mathrm{ml}$. The sulfatide-containing fractions were pooled and lyophilized as above, but with slight warming to help part of the sulfatide dissolve in the cyclohexane. The yield was about $1.06 \mathrm{~g}$.

The composition of the various fractions is indicated in a tlc plate developed with $\mathrm{C}-\mathrm{M}-\mathrm{W}$ (Fig. 1). Sample A shows the entire spectrum of lipids extracted from brain

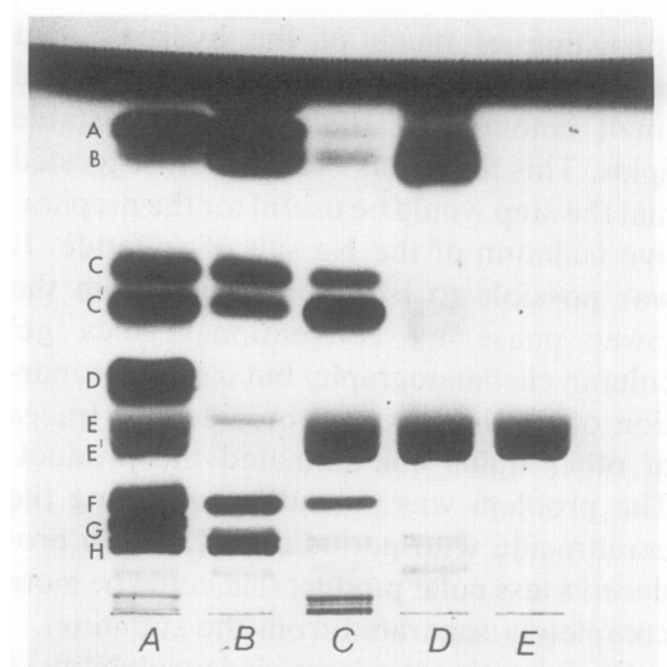

FIG. 1. Thin-layer chromatogram of lipids produced at various stages in the isolation of sulfatide. Sample $A$ is the total extract from pig brain. Band $\mathrm{A}$ is cholesterol, band $B$ is free fatty acid, bands $C$ and $C^{\prime}$ are the two groups of cerebrosides, band $D$ is ethanolamine phosphoglyceride, bands $E$ and $E^{\prime}$ are the two types of sulfatide, band $F$ is lecithin, band $G$ is phosphatidyl serine and probably phosphatidyl inositol, and band $\mathrm{H}$ is sphingomyelin (a double band due to the two clusters of fatty acid chain lengths). Sample $B$ is derived from the upper phase produced by $\mathrm{NaOH}$ addition. Fatty acid esters are visible above the cholesterol and band $\mathrm{F}$ is now lysoplasmalogen. A thin band in the sulfatide region is an artifact due to contamination with bromcresol purple. Sample $C$ is derived from the lower-phase lipids, after neutralizing with acid and partitioning. Sample $D$ represents the sulfatide fraction after treatment with periodic acid and partitioning. The band above the oxidized cerebrosides is probably aldehyde from lysoplasmalogen. Sample $E$ is the final product.

by H-IP. Sample B shows that the supernatant remaining after treatment with alkali contains most of the alkali-stable lipids, the lipoidal cleavage products from the esters-lysoplasmalogen, fatty acids, and fatty acid esters - and very small amounts of lipid in the region where sulfatide would normally be. Sample $C$, derived from the lower layer after neutralizing the $\mathrm{NaOH}$, is evidently largely sulfatide and hydroxycerebroside, but distinct amounts of nonhydroxy cerebroside and lysoplasmalogen 
contaminate the fraction. After treatment with periodate, a large decrease in polarity becomes evident in the cerebrosides and the lysoplasmalogen is largely destroyed, probably because of the acidity of periodic acid.

\section{RESULTS AND DISCUSSION}

A useful step in the isolation of sphingolipids, following extraction of total tissue lipids, is evaporation to remove water and alkali-catalyzed methanolysis in chloroform-methanol. This converts fatty acid glyceride esters to methyl esters and hydrophilic degradation products that are readily removed by solvent partition. When we tried this approach with hexane-isopropanol extracts, we thought that one should use $\mathrm{NaOH}$ in isopropanol, thereby forming isopropyl fatty acid esters that might have use in gas chromatography. However $\mathrm{NaOH}$ is quite insoluble in isopropanol and we accordingly returned to methanolic $\mathrm{NaOH}$. Tests with tlc showed that the reaction was satisfactory. We then tried running the cleavage reaction in the wet $\mathrm{H}$-IP extract, still containing the water from the tissue, and found that this too reacted quite readily. There is therefore no need to evaporate the filtered extract to dryness before carrying out the cleavage reaction.

When alkaline methanolysis is carried out in chloroform-methanol, the reaction mixture can be neutralized and partitioned in one step with aqueous acetic acid. However, when this approach was tried with H-IP solutions, considerable loss of lipid into the aqueous layer occurred. We had previously found that H-IP extracts of tissues could be washed with concentrated aqueous sodium sulfate with only slight loss of lipid, evidently the result of a salting-out effect (12). When this was tried with alkalitreated extracts, including enough sulfuric acid to neutralize the $\mathrm{NaOH}$, the recovery of cerebroside in the upper layer was only $82 \%$. Sulfatide recovery was even lower:
$71 \%$. However, acidification of the lower layer (to $0.05 \mathrm{M}$ sulfuric acid) increased the proportion partitioning into the upper layer. The latter contained $91 \%$ of the cerebroside and $87 \%$ of the sulfatide. Washing the lower layer with H-IP 7:2 (the approximate composition of the upper phase) brought out an additional $4 \%$ cerebroside and $9 \%$ sulfatide. Additional lipid could be recovered by a second extraction of the lower phase, bringing the total recovery to $96-98 \%$.

The procedure finally adopted involves extraction of $1 \mathrm{~g}$ tissue with $18 \mathrm{ml}$ of $\mathrm{H}$-IP $3: 2$, followed by washing of the insoluble residue with $2 \times 3 \mathrm{ml}$ of additional solvent (12). To the filtrate is added $0.5 \mathrm{ml}$ of $5 \mathrm{M}$ $\mathrm{NaOH}$ in methanol and the mixture is vortexed a full minute. The mixture is cloudy and separates partially during the next $10 \mathrm{~min}$. After an additional brief vortexing, $12.5 \mathrm{ml}$ of acidifying solution is added $(6 \mathrm{~g}$ of anhydrous sodium sulfate, $1 \mathrm{ml}$ sulfuric acid, and $98 \mathrm{ml}$ water). This is mixed and the two phases are allowed to separate. About $90 \%$ of the alkali-stable lipids are in the upper phase. Most of the remainder can be brought out of the lower phase by extraction with $2 \times 20 \mathrm{ml}$ of $\mathrm{H}-\mathrm{IP}$ 7:2. A blank run in which lipids were omitted yielded no noticeable sodium sulfate in the washed lipid layer.

The lipid layer probably contains a trace of sulfuric acid; so we add a few drops of ammonium hydroxide solution (1 $\mathrm{ml}$ concd $\mathrm{NH}_{4} \mathrm{OH}+14 \mathrm{ml}$ of isopropanol).

A time study of the reaction of a brain lipid extract with methanolic $\mathrm{NaOH}$ (Fig. 2) showed that the major esterified phospholipids were completely cleaved within 10 min. The phosphatidyl serine was completely cleaved within $1 \mathrm{~min}$ (assayed visually on the tlc plate with ninhydrin) and the lecithin was completely cleaved within $2 \mathrm{~min}$. The ethanolamine phosphoglycerides were more resistant, requiring more than $5 \mathrm{~min}$ but less than 10. Figure 2 shows that the slowermoving region for this lipid was cleaved 
more slowly than the upper region. It is evident from the lysoplasmalogen band (ninhydrin-positive material migrating just below lecithin) that most of the plasmalogen was cleaved within $3 \mathrm{~min}$. The upper part of the tlc plate shows the rapid appearance of both fatty acid esters and free fatty acids.

The rapidity of the alkaline cleavage reaction, which is apparently somewhat greater than that seen with homogenous cleavage in $\mathrm{NaOH}$-chloroform-methanol, may be due to the high $\mathrm{NaOH}$ concentration in the water-methanol phase. The catalysis probably takes place at the interface between the lipid-rich and $\mathrm{NaOH}$-rich phases, and the reaction therefore comes under the category of phase transfer reactions (21). Quaternary amines of the detergent type are generally included in phase transfer reactions; in our system, the sodium salts of free fatty acids and sulfatide may act as the emulsifiers. Sun and Horrocks (22) have shown that ethanolamine phosphoglycerides are quite rapidly cleaved by methanolic $\mathrm{NaOH}$ when the lipids are adsorbed on silica gel. It is likely that this reaction is also an example of phase transfer catalysis, in which the silica gel forms a second phase that partitions off the polar cleavage products from the fatty acid esters.

When we treated cholesterol esters and triglycerides with the standard procedure, described above, we found incomplete cleavage. It was necessary to use heat; $60^{\circ} \mathrm{C}$ for $30 \mathrm{~min}$ was more than enough. The greater resistance of these nonpolar lipids to reaction with alkali is probably due to failure to concentrate at the interface between the two liquid phases. It is likely that more vigorous mixing would be useful.

When the cloudy alkaline reaction mixture from a brain extract was centrifuged to clear it and the upper layer was examined by tlc, we found a marked decrease in the content of hydroxycerebroside and sulfatide (Fig. 1). Only about $6 \%$ of added $\left[{ }^{14} \mathrm{C}\right]-$ sulfatide remained in the upper phase.

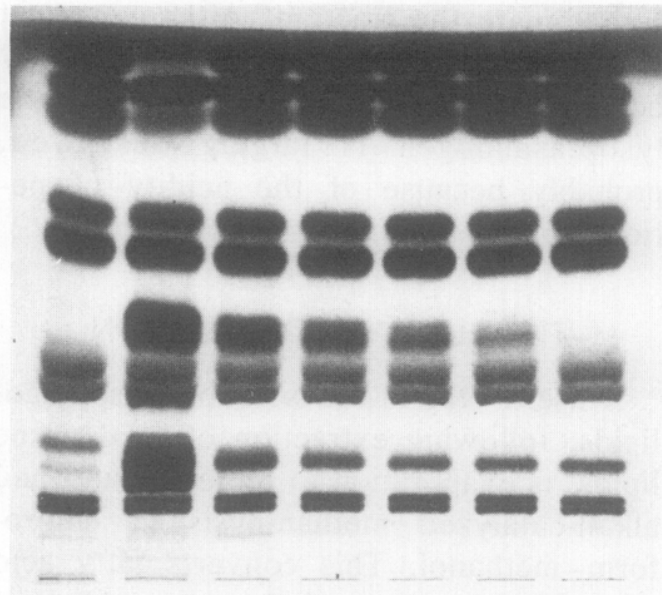

Fig. 2. A time study of the cleavage of ester lipids by alkali. A hexane-isopropanol extract of rat brain was prepared and $5-\mathrm{ml}$ portions were shaken continuously for various time periods with $0.1 \mathrm{ml}$ of $5 \mathrm{~m}$ methanolic $\mathrm{NaOH}$ in a test tube rack vortexer (The Big Vortexer, Kraft Apparatus). Each tube was then vortexed with $2.5 \mathrm{ml}$ of $0.175 \mathrm{M}$ sulfuric acid in sodium sulfate solution. After centrifugation the upper layer was mixed with $0.02 \mathrm{ml}$ of $1 \mathrm{M} \mathrm{NH}_{4} \mathrm{OH}$ in isopropanol and $0.05 \mathrm{ml}$ was applied to a silica gel tlc plate and chromatographed with $\mathrm{C}-\mathrm{M}-\mathrm{W}(65: 25: 4)$. The second sample on the left is the original extract (see Fig. 1 for lipid identifications) and the samples on its right are the results of mixing with $\mathrm{NaOH}$ for $1,2,3,5$, and $10 \mathrm{~min}$.

Attempts were made to remove the $\mathrm{NaOH}$ in the lower phase to allow the isolation of the precipitated lipids. The addition of Dowex $50-\mathrm{H}^{+}$, together with metacresol purple as internal indicator, proved effective on a small scale but the low ionic capacity of the resin made this awkward on a large scale. Neutralization of the alkali with silica gel showed some promise and it may prove useful for small-scale isolations. The use of soluble acids for neutralization, followed by partitioning in a $\mathrm{H}-\mathrm{IP}-\mathrm{W}$ system to remove the salts, led to losses of sulfatide. Despite a variety of trials with the $\mathrm{H}-\mathrm{IP}-\mathrm{W}$ system, we were unable to prevent appreciable losses of sulfate ester. We therefore returned to the $\mathrm{C}-\mathrm{M}-\mathrm{W}$ partitioning system (18), despite the greater hazard and expense in using chloroform. 
Attempts were made to separate the sulfatide from the cerebroside with a silica gel column, using H-IP-W (11), but the solubility of the lipids in such mixtures was rather poor, even at $50^{\circ} \mathrm{C}$. The use of $\mathrm{C}-\mathrm{M}$ with silica gel columns proved surprisingly ineffective, although useful for preparing high purity cerebroside. Enough hydroxy cerebroside trailed into the sulfatide to introduce appreciable contamination, possibly $5 \%$. If this amount of contamination is not objectionable, one can omit the periodic acid step. Another alternative, if both pure cerebroside and sulfatide are desired, is to use a silica gel column to isolate the cerebroside and impure sulfatide, then treat the sulfatide with periodic acid and Florisil. This way only a small amount of cerebroside would be wasted.

At present we cannot explain why the precipitation technique described here yields both sulfatide and hydroxycerebroside so specifically. The addition of methanolic $\mathrm{NaOH}$ clearly acts to form a two-phase partition system and it is not surprising that the sodium salt of sulfatide should preferentially enter the water-rich phase. The fact that cerebrosides accompany the sulfatide suggests that there is an unexpectedly strong physical affinity between the two lipids. It is likely that the addition of methanol to the H-IP extract, without $\mathrm{NaOH}$, would produce two liquid phases in which sulfatide would be a major component. This type of partition might be useful for applications in which the isolation of the ester lipids is also desired.

It may be noted that the scale of the procedure described here can be brought down to a very low sample level and the procedure might have merit as a preliminary step in the quantitative determination of sulfatide, as by the azure blue method (23). The isolation procedure, when run on a small scale, could be speeded considerably by the use of standard methods (pressure instead of gravity for filtration, centrifugation for liquid/liquid partitioning).
The purity of our sulfatide preparation was checked after drying a sample under vacuum with phosphorus pentoxide overnight at $100^{\circ} \mathrm{C}$. The sample lost $2.4 \%$ of its weight, possibly because it contained water of hydration. (Galactosyl and glucosyl cerebrosides also retain solvent and require thorough drying). A check of the dried material by tlc revealed no change in $R_{f}$, so the weight loss cannot be attributed to a dehydration reaction of the allylic hydroxyl group. The elemental composition for the sulfatide was found to be $\mathrm{N}, 1.59 \%$; $\mathrm{S}$, $3.38 \%, \mathrm{Na}, 2.61 \%$ (calculated as the lignoceroyl derivative, $M_{r}$ 912.3: $\mathrm{N}, 1.53 ; \mathrm{S}$, $3.51 ; \mathrm{Na}, 2.51)$. The atomic ratio for the three elements was $0.98: 1.00: 1.07$, respectively.

Comparison of a sulfatide sample by tlc before and after treatment with periodate (19) showed that the material was unaffected. This indicates that the exposure to alkali did not cause migration of the sulfate group. It is possible that some cholesterol sulfate contaminates the sulfatide, but this is likely to be only at the $0.1 \%$ level (24). Treatment with $0.1 \mathrm{M}$ methanolic $\mathrm{HCl}$ for $4 \mathrm{~h}$ converted most of a sulfatide sample to cerebrosides, as reported for sulfatide isolated by another procedure (25). Treatment with $1 \mathrm{M} \mathrm{HCl}$ under these conditions was necessary for complete destruction of sulfatide (some degradation of the cerebroside could be seen on the tlc plate).

Examination of the sulfatide by tlc using $0.1 \mathrm{mg}$ showed no impurities but a very heavy load $(0.5 \mathrm{mg}$ in a band $12 \mathrm{~mm}$ wide) revealed the presence of trace amounts of three contaminants. With a neutral tlc solvent, two bands migrated just above the sulfatide band and the third migrated just below sphingomyelin. With an ammoniacal solvent, which preferentially accelerates the migration of sulfatide, the bands appeared below the sulfolipid. Since the impurities that separated on the tlc plate reacted positively for carbohydrate moieties with an anthrone-sulfuric acid spray, it is likely 
that they were derived from ceramide oligosaccharides that were oxidized by periodic acid. Probably they could be eliminated by first purifying the sulfatide with a silica gel column, then treating with periodate and Florisil.

One consideration that was examined was the question as to whether passing the $\mathrm{Na}$ salt of sulfatide through a Florisil column might result in exchange of $\mathrm{Mg}$ ions for $\mathrm{Na}$ ions. Examination of 1 to $4 \mathrm{mg}$ of sulfatide with Eriochrome Black T at $565 \mathrm{~nm}$ (26), with and without the addition of small portions of $\mathrm{MgSO}_{4}$, showed that no more than $0.7 \mathrm{~mol} \%$ of $\mathrm{Mg}$ could be present.

The yield could be increased if bovine brain is available, as the white matter (a rich source of sulfatide) can be readily dissected out. It should be noted that the oxidized cerebroside isolated in the early fractions from Florisil chromatography could be used for the preparation of a mixture of ceramides (19).

\section{ACKNOWLEDGMENTS}

The authors thank Dan del Vecchio for laboratory assistance. This work was supported by USPHS Grants NS-03192 and HD-07406.

\section{REFERENCES}

1. Wells, M. A., and Dittmer, J. C. (1965) J. Chromatogr. 18, 503-511.

2. Lees, M., Folch, J., Sloane-Stanley, G. H., and Carr, S. (1959) J. Neurochemistry 4, 9-18.

3. Malone, M. J., Stoffyn, P., and Moser, H. (1966) J. Neurochem. 13, 1033-1036.

4. Moser, H. W., Moser, A. B., and McKhann, G. M. (1967) Arch. Neurol. Chicago 17, 494-511.

5. Radin, N. S., Martin, F. B., and Brown, J. R. (1957) J. Biol. Chem. 224, 499-507.
6. Kishimoto, Y., Davies, W. E., and Radin, N. S. (1965) J. Lipid Res. 6, 525-531.

7. Svennerholm, L., and Thorin, H. (1962) J. Lipid Res. 3, 483-485.

8. Rouser, G., Kritchevsky, G., Yamamoto, A., Simon, G., Galli, C., and Bauman, A. J. (1969) in Methods in Enzymology (Lowenstein, J., ed.), Vol. 14, pp. 272-317, Academic Press, New York.

9. Fluharty, A. L., Davis, M. L., Kihara, H., and Kritchevsky, G. (1974) Lipids 9, 865-869.

10. Report on Carcinogenesis Bioassay of Chloroform. Carcinogenesis Program, Div. Cancer Cause \& Prevention, Nat. Cancer Inst., March $1,1976$.

11. Geurts van Kessel, W. S. M., Hax, W. M. A., Demel, R. A., and de Gier, J. (1977) Biochim. Biophys. Acta 486, 524-530.

12. Hara, A., and Radin, N. S. (1978) Anal. Biochem. 90, 420-426.

13. Radin, N. S. (1978) J. Lipid Res. 19, 922-924.

14. Loh, H. H., Law, P. Y., Ostwald, T., Cho, T. M., and May, E. L. (1978) Fed. Proc. 37, $147-152$.

15. Karlsson, K. -A., Samuelsson, Bo E., and Steen, G. O. (1974) Eur. J. Biochem. 46, 243-258.

16. Nonaka, G., and Kishimoto, Y. (1979) $J$. Neurochem. 33, 23-27.

17. Radin, N. S. (1973) in Methods in Enzymology (Ginsburg, V.., ed.), Vol. 28, pp. 300-306, Academic Press, New York.

18. Folch, J., Lees, M., and Sloane-Stanley, G. H. (1957) J. Biol. Chem. 226, 497-509.

19. Carter, H. E., Rothfus, J. A., and Gigg, R. (1961) J. Lipid Res. 2, 228-234.

20. Radin, N. S. (1971) Anal. Chem. 43, 1143-1144.

21. Dockx, J. (1973) Synthesis, 441-456.

22. Horrocks, L. A., and Sun, G. Y. (1972) Res. Methods Neurochem. 1, 230.

23. Kean, E. L. (1968) J. Lipid Res. 9, 319-327.

24. Iwamori, M., Moser, H. W., and Kishimoto, Y. (1976) Biochim. Biophys. Acta 441, 268-279.

25. Stoffyn, P., and Stoffyn, A. (1963) Biochim. Biophys. Acta 70, 107-108.

26. Young, A., and Sweet, T. R. (1955) Anal. Chem. 27, 418-420. 